RUNNING TITLE: Effects of the nature-creativity relationship

3

\title{
An empirical investigation of the relationship between nature engagement, connectedness with nature, and divergent- thinking creativity.
}

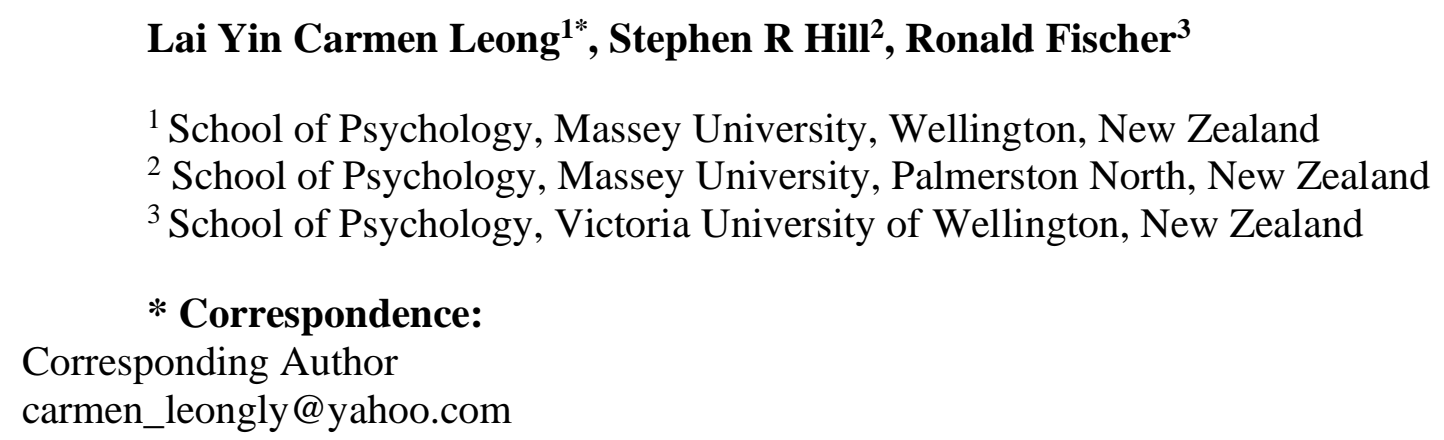

Keywords: divergent thinking, creativity, innovative thinking, creative self-efficacy, outdoor activities, engagement with nature, connectedness with nature 
RUNNING TITLE: Effects of the nature-creativity relationship

\section{ABSTRACT}

15 Previous research has established a positive association between experience of the natural 16 physical environment and creativity. This paper presents two empirical studies that explore the

17 relationships between experiences in nature, the trait of connectedness with nature and

18 divergent-thinking creative performance. Study 1 used a new creativity test to examine

19 divergent-thinking creative performance $(N=141)$. We found significant positive relationships

20 between the Connectedness to Nature Scale and: (a) divergent-thinking creative performance

21 (originality scores), and (b) creativity correlates (innovative thinking and creative self-efficacy).

22 As expected, connectedness with nature predicted originality scores, even after controlling for

23 other creativity-related variables. Students who were more connected with nature generated a

24 greater number of creative ideas, suggesting that connectedness with nature is an important

25 correlate of creativity not accounted for by demographics, physical self-efficacy, and other well-

26 established factors. Building on Study 1, Study 2 is a field experiment $(N=93)$ explored the

27 impact of different types of nature engagements on creativity and established a mediating effect

28 of connectedness with nature. This suggests that focussed nature engagement may facilitate a

29 stronger sense of connectedness with nature, which will, in turn, enhances creativity. It is hoped

30 that our findings will not only influence the way people engage with nature but will also provide

31 an impetus for educational efforts to promote nature connections in outdoor education pedagogy. 
RUNNING TITLE: Effects of the nature-creativity relationship

\section{INTRODUCTION}

The natural environment is important for humankind (Leopold, 1949; Wilson, 1984) as people's 'general engagement with the natural world' has been associated with various positive outcomes such as stress, mood, memory, and creativity (Bowler, Buyung-Ali, Knight, \& Pullin, 2010; Bratman, Hamilton, Hahn, Daily, \& Gross, 2015; Grinde \& Patil, 2009). Such engagement includes the experience of being in a natural environment as well as our personal subjective connectedness with nature. Mayer and Frantz (2004) introduced the term 'connectedness with nature', to describe the extent to which an individual feels and experiences a psychological attachment to the natural world. Having a sense of connectedness with nature has been shown to relate to improvement of individual well-being and individual actions to conserve the natural environment (Markowitz, Goldberg, Ashton, \& Lee, 2012; Mayer, Frantz, Bruehlman-Senecal, \& Dolliver, 2009; Weinstein, Przybylski, \& Ryan, 2009); is correlated with better physical and mental health, pro-environmental attitudes and behaviour, and enhancements in cognitive function (Capaldi, Dopko, \& Zelenski, 2014; Mayer \& Frantz, 2004; Mayer et al., 2009; Tam, 2013). Evidence has also shown that people report psychological benefits when being in pleasant, tranquil natural landscapes (with limited human-made influence), and when exposed to non-threatening aspects of the natural environment (e.g., living things and processes related to life) (Dadvand et al., 2015; Grinde \& Patil, 2009).

Recent studies have also examined creativity variables linked to both exposure to the physical environment and to a psychological connectedness with nature. Research evidence shows that a connection exists between creative performance and exposure to stimuli related to the natural environment (e.g., indoor plants, sounds of nature, and the colour green) (Alawad, 2012; Lichtenfeld, Elliot, Maier, \& Pekrun, 2012; Shibata \& Suzuki, 2002; Shibata \& Suzuki, 2004), or the experience of being in a natural environment (Atchley, Strayer, \& Atchley, 2012; Ferraro, 2015). Some researchers (Atchley et al., 2012; Ferraro, 2015) have found that immersion in nature increases our convergent thinking-related creative performance, i.e., our ability to produce a correct creative solution (Guilford, 1956; Mednick, 1962). In comparison with a control group, people who engaged in outdoor activities performed about $50 \%$ better in coming up with the correct solution when doing convergent-thinking tasks. Even, individuals exposed to an indoor plant performed better in association tasks (Shibata \& Suzuki, 2002; Shibata \& Suzuki, 2004). People who feel a close connection with nature have reported greater perspective-taking ability (Herzog, Black, Fountaine, \& Knotts, 1997; Mayer \& Frantz, 2004) and prefer more innovative thinking (Leong, Fischer, \& McClure, 2014). Leong et al. (2014) reported that connectedness with nature is positively correlated with creative cognitive styles among adolescents, even when controlling for covariates such as positive affect and well-being. All these studies have linked connectedness with nature and innovative thinking, but we do not know whether these effects can be translated into actual creative performance in natural environments. There is thus a need to further clarify the relationship between connectedness with nature and creativity because current knowledge of such effects remains limited.

A number of studies have used correlational designs and focused on creative preferences (rather than performance). Within the nature-creativity literature, some studies focused on the creative effects of visual/auditory natural stimuli (e.g., green plants and sounds of nature) (Alawad, 2012; Shibata \& Suzuki, 2002; Shibata \& Suzuki, 2004), or the experience of being in natural environments (Atchley et al., 2012; Ferraro, 2015). Thus, we know very little about the 
RUNNING TITLE: Effects of the nature-creativity relationship

link between connectedness with nature and creativity performance. Furthermore, while studies suggest that nature exposure might increase creativity (Atchley et al., 2012; Ferraro, 2015), the robustness of such findings is unclear since no comparable control conditions were used. The lack of adequate control conditions constitutes a barrier to effective investigation because the effects of nature exposure on creativity have traditionally been tested against a waitlist control group (limited physical activity or nature exposure) or an urban environmental exposure condition (e.g., Atchley et al., 2012; Ferraro, 2015). Therefore, significant confounding factors such as walking (Oppezzo \& Schwartz, 2014), or cognitive stressors associated with navigating in a busy city environment, might explain the differences between the nature exposure and control conditions.

Finally, we currently do not know if exposure to the natural environment will facilitate divergent-thinking creative performance, i.e., the capability to generate as many creative ideas as possible (Guilford, 1950,1956), as, to date, research has focussed on convergent-thinking creative performance (Atchley et al., 2012; Ferraro, 2015; Shibata \& Suzuki, 2002; Shibata \& Suzuki, 2004). A creative product can be generated by cognitive processes such as divergent and convergent thinking (Ma, 2009). Divergent thinking was first related to creativity in the theory of divergent production (Guilford, 1950, 1956), and aims to generate creative ideas by exploring diverse solutions to one problem. On the other hand, convergent thinking focusses on producing the perfect creative solution appropriate for the problem (Mednick, 1962). These two cognitive processes measure different creative outcomes, the first focussed on the production of a diversity of useful and original ideas, the second on the production of a single and accurate idea. Both processes have been identified as benefitting from exposure to nature (Atchley et al., 2012; Ferraro, 2015; Lichtenfeld et al., 2012; Shibata \& Suzuki, 2002; Shibata \& Suzuki, 2004). Therefore, to understand nature relationships with creativity, it is important to test divergent thinking (in addition to convergent thinking as in previous studies).

Our paper focusses on how 'general engagement with the natural world' (i.e., both connectedness with nature (Study 1) and actual experience of being in natural environment (Study 2)) relate to creative performance. We examined creative performance by using divergent thinking tasks, instead of focussing on the production of a single best solution for convergent tasks. The rating of a produced item or an idea will be considered creative if "it is both novel and appropriate, useful, correct," and if the task is heuristic with open-ended answers rather than a single correct solution (Amabile, 1983b, p. 360). The first study clarifies the relationship between connectedness with nature and creative performance (divergent thinking). The second study, a field experiment, explores whether focused nature experience (compared to a control condition) enhances creative performance. In the discussion, we outline some general mechanisms that may influence this link and can be tested in more detail in future studies.

\section{STUDY ONE}

The primary goal of study one was to explore the relationship between subjective connectedness with nature (a psychological nature-related variable) and actual creative performance. Building on previous findings (Atchley et al., 2012; Ferraro, 2015; Leong et al., 2014; Shibata \& Suzuki, 2002; Shibata \& Suzuki, 2004), we hypothesize that individuals who are connected with nature will also be more likely to generate diverse creative ideas. Given the nature of correlational analysis, it is possible that creativity may increase our connectedness or a 
RUNNING TITLE: Effects of the nature-creativity relationship

125 third variable might be responsible for the correlation between the two variables of interest. For example, an innovative thinking style may be associated with both creative performance and connectedness with nature. As Leong et al. (2014) has eliminated the positive emotion explanation in an earlier study, we will focus on other creativity-related correlates. In summary, our first study aims to answer the research question: Does connectedness with nature relate to creative performance beyond alternative variables such as creative traits or cognitive styles?

\section{MATERIAL AND METHODS}

\section{Participants}

A total of one hundred and eighty-five school students (47.0\% of them female) from two Singapore schools volunteered to participate in the study. This sample had adequate power to detect an effect of $d=.34$ (Faul, Erdfelder, Lang, \& Buchner, 2007), based on a metaanalytically derived overall effect size estimate of the effectiveness of outdoor activities (Hattie, Marsh, Neill, \& Richards, 1997). These students completed the Outdoor Creativity Task (OCT) form A (see Materials for more details) and their mean age was 13.45 years $(S D=2.15)$, with a range from 13 to 16 years. To avoid fatigue effects, a few days later, a second session was conducted with an alternative form of the OCT and questionnaires including demographic information and various psychological scales at Time 2. 141 of the original 185 participants (49.7\% female) completed the surveys given the lower school attrition rate during end-of-year after examinations period. The mean age of this second group was 13.66 years $(\mathrm{SD}=.78)$, with a range from 13 to 16 years. Written consent from school principals of involved students were obtained prior to the study, aligned with the school research ethics protocol.

\section{Materials}

Dependent variable: Creative performance. For the purposes of this study, the Outdoor Creativity Task (OCT) was designed specifically to assess divergent-thinking creative performance. We chose to design this new measure because some divergent thinking tests consisted of a single creativity task, so may have lacked dependable scores (Silvia et al., 2008), and previous studies have shown that customised divergent-thinking tests improve the capacity to identify creative talent (Lee, Therriault, \& Linderholm, 2012). This section briefly covers the items, the forms administered, the scoring method, and the measurement (for more details, please see Leong (2017)).

There were ten open-ended items that required participants to generate as many solutions as possible. These ten items consisted of both general and nature-related tasks requiring divergent thinking. Some tasks, for instance, required participants to find unusual uses or improvements for common items; some called for creation of new ideas or inventions; and others tapped into participants' ability to generate solutions to a problem. There was no stipulation that individuals needed to create nature-related ideas when solving the problems. Preliminary results showed similar correlational patterns for both types of tasks. Examples of the ten items include: "Think of as many possible improvements as you can to a regular backpack, making it more interesting, more useful, and more presentable", and "Many tourists are visiting our nature reserves but are unaware of the dos and don'ts to observe in nature. What steps can you suggest to communicate the necessary guidelines to our tourists?" 
RUNNING TITLE: Effects of the nature-creativity relationship

The OCT comprised two forms, Form A and Form B, because the test was designed for pre-post-test comparison in future studies. The two forms consisted therefore of similar tasks. A participant might be required, for example, to think of as many possible uses as he/she can for different elements, e.g., a rock in Form A and a tree $\log$ in Form B. Each form consisted of five three-minute divergent-thinking activities.

The test was scored by using a subjective scoring method based on the widely used and validated Consensual Assessment Technique (Amabile, 1983a). Two coders were involved. They also used the Silvia et al.'s (2008) guidelines to standardise the coders' general understanding of creativity when judging. Consistent with the creativity scoring procedure in Lee et al. (2012), coders first determined the number of ideas generated for each activity. Any redundant or repeated items were counted once only. Next, the originality score for each counted response was coded on a five-point Likert scale, ranging from 1 (not at all) to 5 (very much). The originality scores showed good inter-class reliability (intraclass correlation coefficient $[\mathrm{ICC}]=.72$ ). According to Amabile (1996), this is an adequate level of inter-rater reliability, and is similar to the range of .70 to .89 for previous inter-rater reliability correlations. Runco (1986) argues that the originality scores typically relate closely to the number of ideas generated, and our results are consistent with this $(r$ $=.97, p<.01)$.

Originality scores are used as an indicator of divergent-thinking creative performance. The originality scores for all creative ideas produced for each task were combined to measure that task's overall creative strength: A high score suggests a greater capability to produce more creative ideas. All ten items were combined as a single creativity scale, and the Cronbach's alpha for the originality scores of the ten OCT items was .86.

Independent variable: Connectedness to nature. The Connectedness to Nature Scale (CNS) measures the level of one's general connectedness with nature (Mayer \& Frantz, 2004). There are 14 items, which include statements such as "I think of the natural world as a community to which Ifeel belong to" and "I often feel disconnected from nature" (reverse scored). Participants indicated how strongly they agreed or disagreed with each item on a five-point Likert-type scale, ranging from 1 (strongly disagree) to 5 (strongly agree). The Cronbach's alpha was .76.

Control variable: Adaptive-innovative thinking. The Kirton Adaption-Innovation Inventory (KAI) assesses whether participants' preferred thinking style is more innovative or adaptive oriented (Kirton, 1976). There are 32 items: An example item from the innovative end is "always full of ideas" while an adaptive item example is "is organised and efficient". Participants rated how well each item described them using a five-point Likert-type scale. This ranged from 1 (not at all like me) to 5 (just like me), which gave a possible range of 32 to $160 \mathrm{KAI}$ scores. A lower KAI score suggests a more adaptive preference, and a higher score a more innovative one. The KAI scale was found to be reliable $(\alpha=.93)$.

Control variable: Creative self-efficacy. The Creative Self-Efficacy scale (CSE) assesses an individual's belief in his/her own creative ability to generate novel and useful ideas or products (Tierney \& Farmer, 2002). The three items were adapted from Beghetto (2006) and included "I am good at coming up with new ideas", "I have a lot of good ideas", and "I have a good 
RUNNING TITLE: Effects of the nature-creativity relationship

imagination". Participants rated on a five-point Likert-type scale ranging from 1 (not true) to 5 (very true) how accurately each item/statement conveyed their view. A higher CSE score indicates a greater level of self-belief regarding one's own creative ability. The scale was reliable $(\alpha=.83)$.

Control variable: Physical self-efficacy. The Perceived Physical Ability Scale for Children (PAS) assesses an individual's physical self-efficacy, i.e., belief in such physical abilities on his/her part as strength and speed (Colella, Morano, Bortoli, \& Robazza, 2008). We included this measurement of physical self-efficacy because one reviewer suggested that physical fitness might be an underlying effect driving the effect between creativity performance and connectedness with nature. To partial out any activity-related effects of outdoor experience on creativity, we controlled, therefore, for the participants' physical self-efficacy while examining the effects of connectedness with nature and creativity. In this scale, the six items were adapted from Ryckman, Robbins, Thornton, and Cantrell (1982). Participants rated how accurately each item/statement conveyed their own views of their physical ability on a four-point Likert-type scale ranging from 1 to 4. An example item included scores of 1 (I run very slowly), 2 (I run slowly), 3 (I run fast), and 4 (I run very fast). This scale gave a possible range of 6 to 24 PAS scores. A lower PAS score suggests a perception of having less physical ability, and a higher score a stronger sense of physical self-efficacy. The PAS scale was reliable $(\alpha=.73)$.

\section{Procedure}

Prior to this study, to ascertain the age appropriateness of the OCT forms and questionnaires, we seek inputs and approval from the school teachers and conducted a focus group discussion with a group of students aged 13-15 years to discuss their understanding of the question items. The participants completed two of the OCT forms over two sessions. ${ }^{1}$ Timed by the researcher (three minutes per task), they completed a total of five divergent thinking tasks in each OCT form. During the second session, after finishing the tasks for the second OCT form, the participants also completed a questionnaire that included demographic information and various psychological scales.

\section{Statistical Analysis}

There were some considerations regarding demographics that might influence our results. The first issue links to educational status. Although creativity studies have shown a negligible link between intelligence and creativity (Kim, 2005), the educational status of express and normal streams ${ }^{2}$ for different year groups was used as a control variable in this study. The second issue relates to the participants' contact with nature. Given the green city policy and the landscape in Singapore, all participants would have had frequent exposure to urban nature (e.g., to neighbourhood parks and roadside trees) and nature-related stimuli (e.g., potted plants). All

${ }^{1}$ The OCT is designed as a pre-post test for the purposes of the first author's PhD project. Given that the items on the two forms tap into a set of similar divergent tasks, one concern relates to participation fatigue as a result of completing two creativity forms and a questionnaire. To overcome this challenge, students were given the second form to complete a few days later.

${ }^{2}$ As Singaporean secondary students are streamed according to their scores for the national primary school leaving examinations, the proportion of participants studying in the express stream was $80.4 \%$, whereas $19.6 \%$ were in the normal stream. Generally, the normal stream students who study for five years are viewed as low achieving: the majority will spend four years in the express stream during their secondary school education. 
RUNNING TITLE: Effects of the nature-creativity relationship

participants lived in urban parts of Singapore, in close proximity to their schools. The neighbourhoods of participating students are categorised as 'non-mature estates', and typically include high-rise apartments as well as human-made parks with plants and small trees. The level of familiarity with nature would therefore be largely homogenous for this sample. Another possible confound would be their outdoor exposure through school-organised camps. Given the educational context in Singapore, ${ }^{3}$ a way of differentiating students' contact with nature is through their attendance in outdoor camps. ${ }^{4} 16.1 \%$ of the participants reported that they had never before attended an outdoor camp, $21.7 \%$ had attended only one, $25.2 \%$ two, $13.3 \%$ three, and the remaining $23.7 \%$, more than three. As there may be a possible link between their outdoor experience and creativity, we include this as a control variable in our analysis.

To better understand the role of nature in creativity, a hierarchical multiple regression analysis was performed to explore the predictive validity of connectedness with nature for creativity, by controlling for demographics, physical self-efficacy (to partial out any activityrelated effects of outdoor experience on creativity), and creativity-related variables.

\section{RESULTS}

Table 1 shows all the statistically significant correlations between the overall Outdoor Creativity Task (OCT) scores for originality and variables such as connectedness to nature (CNS), innovative thinking (Kirton's Adaption-Innovation Inventory: KAI), creative self-efficacy (CSE), and physical self-efficacy (PAS). As expected, originality scores correlated significantly with the Connectedness to Nature Scale, innovative thinking style, and creative and physical self-efficacy. In other words, creative students are more likely to (a) be connected to nature, (b) prefer to think "outside the box" when solving problems, and (c) believe that they are creative and physically fit. The Cohen's (1992) effect size values for originality scores suggested low to medium practical significance.

A hierarchical multiple regression analysis was used for originality scores (see Table 2). There were no multicollinearity problems (VIF = 1.12 for PAS, 1.74 for KAI, 1.44 for CSE and 1.52 for CNS), and other assumptions were met. To investigate the role of connectedness with nature in the prediction of creativity scores, originality was regressed on CNS, after controlling for alternative explanations (i.e., demographics, physical self-efficacy, and creative personality). At Step 1, we added age, gender, educational status, outdoor experience, and physical self-efficacy.

${ }^{3}$ Generally, a typical Singaporean student has little outdoor experience, as most of his or her time outside formal school hours is spent on activities intended to help him/her achieve good academic results; home tuition, for example, or after-school remedial lessons. Most formal physical activities are conducted within school compounds, either on a football field or in an indoor sports hall.

${ }^{4}$ A standard outdoor school camp in Singapore managed by the Ministry of Education often includes a residential area for campers and a human-made challenge course. Most camp duration appears to last 3 days and 2 nights but the actual camp duration is two and a half days because the last day involves only half a day of packing up and breaking camp activities. Most camp programmes, then, have revolved around challenge course activities such as artificial rock-climbing, abseiling, and high-rope elements. Some campsites may overlook or be immediately beside a natural setting (a coastal area, for example), but will usually be no more than a minute's walk from public transportation, industrial parks or housing areas. Given their camping experience, most participants would have been exposed to some human-made materials included in our test (e.g., a climbing helmet). 
RUNNING TITLE: Effects of the nature-creativity relationship

At Step 2, we entered two creativity-related indicators (KAI and CSE); and at Step 3, CNS was entered.

As predicted connectedness with nature emerged as a significant predictor for originality scores, beyond alternative explanations such as demographics, physical and creative self-efficacy, and innovative thinking. The combined predictors accounted for $19.7 \%$ of the variance $\left(R^{2}=.20, F\right.$ $(8,132)=4.05, p<.01)$ at Step 3 of the regression. Creativity-related variables explained 5.5\%, and the Connectedness to Nature Scale explained an additional $4.7 \%$ of the variance in originality scores. CNS (standardised $\beta=.27, p<.01$ ) significantly predicted creativity scores, $\Delta F(1,132)=7.77, p<.01$. In this model, for every increase of 1 in the connectedness score, there was an increase of 2.87 in the number of original ideas created, 95\% CI [.83, 4.91].

\section{DISCUSSION}

Two noteworthy findings emerged. First, divergent-thinking creative performance showed significant associations with two conceptually-related variables of creativity (creative self-efficacy and Kirton's (1976) adaptive-innovative thinking) as well as with the Connectedness to Nature Scale. Importantly, divergent-thinking creative performance was positively associated with connectedness to nature. This finding extends previous creativity research that focussed strictly on the link between the physical natural environment and creativity, typically using convergent thinking (Atchley et al., 2012; Ferraro, 2015; Shibata \& Suzuki, 2002; Shibata \& Suzuki, 2004). This supports our speculation that connectedness with nature is also associated with divergent-thinking creative performance. Our results also converge with related research reporting a relationship between creative performance and creativity-related variables (Beghetto, 2006; Ee et al., 2007; Ma, 2009; Tierney \& Farmer, 2002), such as efficacy and innovative thinking style. Overall, people who generate more creative ideas are more likely to have a close connection with nature, strong creative self-efficacy, and an innovative thinking style.

Second, and more importantly, after including demographics, physical self-efficacy, and creativity correlates as control variables, connectedness with nature was a significant statistical predictor of originality scores. Our data also suggest that this relationship is not due to another third variable such as innovative thinking, for example. While our findings suggest that alternative explanations, e.g., innovative thinking and self-efficacy, may not explain the link between connectedness with nature and creativity, our data are still correlational. There is a need for an experimental design to further clarify the causal direction of the link. In addition, we examine whether being connected with nature will act as a mediator between nature exposure and creative performance.

\section{STUDY TWO}

Building on the findings in Study 1, Study 2 investigated whether connectedness with nature plays a role in explaining the relationship between engagement with nature and divergentthinking creative performance. 
RUNNING TITLE: Effects of the nature-creativity relationship

First, we tested whether active engagement with nature is necessary for the production of positive connectedness with nature effects. Nature experiences appear to depend on how people engage with their environment and how deep their connection with nature is. While some studies have reported that exposure to or immersion in nature results in greater connectedness with nature (Mayer \& Frantz, 2004; Mayer et al., 2009; Weinstein et al., 2009), Vining, Merrick, and Price (2008) argue that this sense of connectedness may vary depending on one's experiences with nature. A sense of connectedness will perhaps depend not just on immersion in nature, but also on the way we engage with nature. How we engage with nature may influence how strongly connected we feel to it (Vining et al., 2008). Such individual differences aside, we propose that active engagement with nature is a key step in enhancing the individual's connectedness with nature.

Second, we test whether engagement with nature influences connectedness with nature and, in turn, facilitates divergent-thinking creative performance. Mayer et al. (2009) investigated the mediating role of connectedness with nature on the relationship between exposure to nature and cognition. They reported that a creativity-related cognitive outcome (the ability to reflect) was improved after a walk in a nature reserve (as opposed to a walk in an urban setting) and that this effect was partially mediated by connectedness with nature. When comparing highly controlled nature conditions (virtual versus actual nature), they also reported that connectedness with nature marginally mediated the effects of condition on the ability to reflect. This indicates that connectedness with nature may play a role in influencing cognitive outcomes after exposure to nature.

In summary, Study 2 aims to test whether individuals need to engage purposefully with nature to produce positive effects on creativity, or whether nature exposure (without active attention being given to nature) is in itself sufficient to promote creativity. We tested whether a brief nature walking intervention, where participants were instructed to consciously pay attention to the natural environment, was more effective in improving creative performance than a similar exposure in which participants' attention was not centrally focussed on the natural environment. We predicted that focussed engagement with nature would improve creative performance. In other words, after a focussed engagement with nature, the creative performance of the focussed engagement group will improve compared to the performance of a non-focussed engagement group. We also predicted that the effect on creativity scores of engaging with nature would be mediated by a person's feeling of connectedness with nature.

\section{MATERIAL AND METHODS}

\section{Participants}

Ninety-three university student volunteers $(M=25.93$ years; $73.6 \%$ female $)$ participated in the study. Power analysis using the average meta-analytic effect size of nature exposure across all outcomes (Hattie et al., 1997) and a beta level of .80 suggested a sample of 70 for the required total number of participants. This means that our study was sufficiently powered (Faul et al., 2007). Written consent from volunteers was obtained prior to the experiment.

\section{Materials}


RUNNING TITLE: Effects of the nature-creativity relationship

Creative Outdoor Adventure Task. We used two five-item versions of the Creative Outdoor Adventure Task (adapted from various divergent thinking creativity measures (Lee et al., 2012; Leung \& Chiu, 2010; Leung, Maddux, Galinsky, \& Chiu, 2008)) to measure creativity (divergent thinking). Participants were required to generate as many ideas as possible for each item within a span of three minutes. A sample item includes "Think of as many possible improvements as you can to a regular backpack, making it more interesting, more useful and more presentable". Two coders, blind to the experimental conditions and hypotheses of the study, were asked to evaluate on a 5-point scale (from $1=$ very uncreative, to $5=$ extremely creative) the originality of each idea produced. A high score suggests a stronger capacity to produce creative ideas (for more information on the validity, see Amabile (1983a), Silvia et al., (2008)). The originality ratings showed good intraclass reliabilities (intraclass correlation coefficient $[\mathrm{ICC}]=.82 \& .73$, for time 1 and time 2 respectively). The average scores across the two coders were used to measure creativity.

Connectedness to Nature Scale. We measured the more stable dispositional aspect of connectedness with nature at time 1, using the Connectedness to Nature scale (e.g., "I think of the natural world as a community to which I feel belong to" and "I often feel disconnected from nature" (reverse scored))(Mayer \& Frantz, 2004). At time 2, we measured the state level or spontaneous feeling of connectedness with nature with an adapted version of the Connectedness to Nature Scale (e.g., "Right now, I feel a sense of togetherness with the natural world around $m e$ ") (Mayer et al., 2009; Weinstein et al., 2009). A higher score indicated greater levels of connectedness with nature (rated on a 5 -point Likert scale, from $1=$ strongly disagree, to $5=$ strongly agree). The reliability was .74 at time 1 and .79 at time 2 .

\section{Procedure}

The study used a 2 (Engagement in nature: Nature focussed versus unfocussed) x 2 (time: before versus after) mixed measures design. It took place within the world's first fully fenced ecosanctuary, situated in a valley on the outskirts of Wellington, New Zealand. The participants were recruited through two New Zealand universities' social media to participate in a research study at the eco-sanctuary. Upon arrival at the eco-sanctuary, participants completed a version of the creativity test, a connectedness with nature survey, and demographics-related information (time 1). They were then randomly assigned to a treatment condition specified on a personal activity sheet. This activity sheet (collected at the end of the walk) required participants to record either their observations, or their tally of footsteps and reflections, at various checkpoints. In the unfocussed attention condition, participants were instructed to count their footsteps during the walk and to reflect, at seven checkpoints along the way, on personal experiences unrelated to nature (they were asked, for example, to write a sentence about a recent university paper or about a meal eaten last week). In the focussed attention condition, participants were instructed to pay attention to specific aspects of the natural environment while walking (e.g., the sounds of nature heard and the birds seen), and to reflect on nature-related experiences at the checkpoints. Questions about the procedure were answered on an individual basis and participants were instructed not to communicate with one another while walking. Post-experimental debriefs suggested that our manipulations were successful and that individuals were unaware of the different activities given to other participants. Having received their individual tasks, people walked in groups of four to seven. The joint walking of people assigned to the two different conditions allowed us to control for weather and for environmental and social conditions, with the major difference being the 
RUNNING TITLE: Effects of the nature-creativity relationship

experimental condition assigned to each individual during the walk. All groups were led by the same researcher along the same walking track, which followed a sealed road beside a lake in the valley (approximately 500m), then a well-graded dirt road through some undergrowth (approximately 800m). Participants then walked beside a stream (approximately $600 \mathrm{~m}$ ) and came back to the sealed road for the return to the Visitor Centre. After the walk, which lasted approximately 40 minutes, participants completed the second set of the creativity test and the connectedness with nature survey (time 2 measures), both in the same location. Each participant was given a movie voucher to compensate him/her for the time given to the study.

\section{RESULTS}

There were no pre-existing differences between the two conditions in terms of trait connectedness with nature $F(1,91)=.23, p=.63$, and creativity scores, $F(1,91)=.11, p=.74$. Table 3 shows all the statistically significant correlations between the scores for originality at both times, and connectedness with nature at time 2 . Originality scores after walking in nature correlate significantly with connectedness with nature scores at time 2 . These significant correlations establish a link between connectedness with nature and creativity scores such as originality after nature experiences.

To test our main hypothesis, we conducted a mixed measures ANOVA to examine the effects of condition on creativity scores. The main effect for time was not significant: $F(1,91)=$ $.04, p=.85, \eta_{p}^{2}=.00$; nor the main effect for nature engagement manipulation: $F(1,91)=.78, p$ $=.38, \eta_{p}{ }^{2}=.01$. There was a marginally significant trend (one-tailed) for an interaction between time and nature engagement manipulation: $F(1,91)=2.53, p=.06, \eta_{p}^{2}=.03$ (see Figure 1 for a visual display of the overall findings). We further explored the simple effects by conducting two dependent $t$-tests. Although non-significant, our results indicated the trend of a small decrease in creativity scores from time 1 to time 2 for the control group: $t(46)=1.01, p=.32,95 \%$ CI [-.42, 1.24], Cohen's $d=.30$; and a small creativity increase over time for the focussed group: $t(47)=-$ $1.24, p=.22,95 \%$ CI $[-1.39, .33]$, Cohen's $d=-.37$. These effect sizes are comparable to a previous meta-analytical effect size of .34 (Hattie et al., 1997) and to the effect size (.41) of Leong (2017) for the effectiveness of outdoor programmes in pre-post-test studies. Furthermore, an independent $t$-test analysis revealed that the focussed engagement group had higher creativity scores at time 2, compared to the non-focussed engagement group: $t(91)=1.36, p=.18,95 \% \mathrm{CI}$ $[-.58,3.12]$, Cohen's $d=.28$. Although there is not sufficient evidence to reject the null hypothesis, the estimate of the effect size is comparable to the effect size of .26 reported in Leong (2017) for the effectiveness of outdoor programmes in experimental studies.

Next, to test whether our manipulation of engagement in nature indeed had an influence on creativity performance through subjective feelings of connectedness with nature, we performed a mediation analysis, using 5000 bootstrapping resamples and bias-corrected $95 \%$ confidence intervals (Hayes, 2012). Figure 2 displays the results. The experimental manipulation was marginally significant for connectedness with nature $(B=.27, t(91)=1.93, p=$ $.06)$, whereas the experimental manipulation effect on creativity $(B=1.27, t(91)=1.36, p=.18)$ was non-significant. The path from subjectively rated connectedness with nature to creativity $(B$ $=1.52, t(90)=2.20, p<.05)$ was significant. Importantly, the indirect effect of engagement with nature on creativity through connectedness with nature was significant $(B=.41 ; \mathrm{CI}=.03$ to 
RUNNING TITLE: Effects of the nature-creativity relationship

1.15). In other words, connectedness with nature mediated the association between the engagement with nature manipulation and originality scores.

We also tested the homogeneity of regression slopes to rule out possible interactions between the engagement with nature manipulation (IV) and connectedness with nature (mediator). No significant interaction was found: $F(1,89)=3.20, p>.05, R^{2}=.03$. In other words, the relationship between connectedness with nature and originality scores did not change as a result of the engagement with nature manipulation, and, inversely, connectedness with nature did not affect the association between our manipulation and originality scores.

\section{DISCUSSION}

Study 2 presents a rigorous examination of the nature-creativity argument and suggests a general trend of higher creativity after a focussed engagement with nature manipulation. Although the effects were insignificant, we reported a small to moderate effect size of .37 for an increase in creativity over time, which was comparable to the benchmark of previous metaanalyses for outdoor programmes (Cason \& Gillis, 1994; Hans, 2000; Hattie et al., 1997; Leong, 2017). Our findings point to the mediating effect of connectedness with nature on nature engagement and creativity.

\section{GENERAL DISCUSSION}

To our knowledge this paper is the first to explore the relationships between actual experiences in nature, connectedness with nature, and divergent-thinking creative performance. Instead of using a prolonged nature experience as earlier studies have done (Atchley et al., 2012; Ferraro, 2015), Study 2 examined a more practical and cost-effective approach, which could be achieved in other contexts by taking a short nature walk during lunch breaks, classroom activities, etc. This study also breaks new ground in that by having participants follow the same walking route for both conditions (focussed and unfocussed engagement with nature), it controlled confounding variables such as physical and cognitive demands. We compared effects on creative performance by using the same natural environment, but changing the focus of attention. These advances allow us to better estimate the effect of engagement with the natural world than may have been achievable in previous research where important factors were not controlled (Atchley et al., 2012; Ferraro, 2015). Experiments conducted in the natural environment allow us to study participants in a more authentic setting than is possible within a laboratory. This offsets, to some extent, the limitations resulting from limited experimental control over extraneous situational factors.

Given the highly controlled nature of Study 2 (i.e., a number of confounds in previous studies were ruled out to compare a nature-focussed versus nature-unfocussed engagement manipulation in real world settings), it is, perhaps, not surprising that the mediating effect size is significant but relatively small. Previous studies used weaker controls and found relatively strong effects. In our more stringent test, connectedness with nature was found to mediate the relationship between creativity and focussed engagement with nature, even though the direct effects were only marginally significant. Our findings overall are consistent with those of Mayer et al. (2009), who a) for natural versus urban conditions found a mediating effect of connectedness with nature on the relationship between nature and the ability to reflect, and b) a 
RUNNING TITLE: Effects of the nature-creativity relationship

508 marginal mediating effect when comparing highly controlled nature conditions (virtual versus actual nature). Although the study did not provide significant evidence that the active engagement group was more creative than the passively engaged group, there is stronger evidence that it does for those people who had higher connectedness with nature after the walk. This suggests that some people even when asked to 'engage' might not get that much out of the experience of the walk if they do not connect with the natural environment.

What might explain the relationships between nature connectedness, exposure to nature and creative performance? One possibility is that these relationships operate via increased perspective taking (e.g., Mayer \& Frantz, 2004). When solving problems, divergent thinking allows a person to brainstorm and generate diverse creative ideas before using convergent thinking to decide on the most appropriate idea (Ma, 2009). Divergent thinking probably requires perspective taking and outside the box thinking in order to produce a variety of novel ideas. One way of generating a creative idea may involve perspective taking through an understanding of the preferences, values, and needs of others. Grant and Berry (2011) argued and found that this ability to adopt the perspectives of others may direct a person to focus on generating not merely novel but also useful ideas relevant to a problem. Similarly, this perspective taking has been found to be linked to subjective connectedness with nature (Mayer \& Frantz, 2004). Furthermore, exposure to nature involves individuals stepping out of their day-to-day environments in modern societies, which may foster a proverbial outside the box attitude. These previous studies and arguments suggest that perspective-taking ability appears to be shared by both creative people and people who are connected with nature. People who have a strong sense of connectedness with nature seek such connections in a variety of ways: by identifying with nature, for example, and/or by taking a perspective that considers the impact of human beings on the natural world (their own impact, or that of others) (Mayer \& Frantz, 2004). Such a perspective requires consideration of diverse viewpoints during decision-making. Additionally, people with a greater sense of connectedness are possibly more likely to appreciate the interconnectedness within the natural world and to understand how, in its complexity, nature solves problems (e.g., relationships within ecosystems, food webs, and life cycles). This knowledge of nature may provide different perspectives as to how things work and possibly broaden cognitive resources. With the new perspectives as additional resources, individuals may be able to solve complex problems and put things together in novel ways.

Alternatively, the restorative effects experienced by people whose professions are not related to natural environments may be explained by a classic conditioned response (Pavlov, 1927). As most people now live in urban areas (United Nations Population Division, 2014), they probably mostly go to parks and green spaces during their free time. Such natural environments might be associated (via classical conditioning) with free time, with being off work, or on a holiday, and being in nature then activates the positive psychological and physiological states embodied in those activities. These conditioned positive emotions may therefore lead to other positive psychological responses (e.g., creative thinking) when in nature. For example, Isen (1999) argued that positive affect encourages creative thinking, as happy people are more likely to make links between ideas and see a variety of connections between stimuli. Broaden-andBuild Theory (Fredrickson, 2001) proposes that people are more likely to play, explore, and learn when they are feeling positive, and this positivity enhances their capacity to focus, think, 552 and act. Combining the conditioned positive emotions from being in natural areas with the 553 insights from Broaden-and-Build theory, these positive associations of being in nature may 
RUNNING TITLE: Effects of the nature-creativity relationship

554

encourage the process of play and exploration, which in turn may positively influence our thoughts and creative thinking. This mechanism may also explain why adults working in forests or children from agricultural work backgrounds do not experience restorative effects when spending free time in natural areas (Collado et al., 2016; von Lindern et al., 2013). For these people, spending free time in natural areas is associated with work and routine rather than on a holiday and they may feel less positive when in natural areas. However, the study by Leong et al. (2014) which controlled for positive emotions as an alternative explanation suggested that nature connectedness effects on creative thinking styles.

Therefore, the mechanisms that drive the effects reported in our study are open for further study. Various theoretical mechanisms might play a role, including shifts in perspective taking as well as conditioned positive affect when engaging with restorative natural environments.

\section{Limitations and Future Research}

First, unlike classical laboratory experiments, running experiments in the natural environment might present certain levels of bias. Each experimental session comprised two conditions concurrently in that participants from both conditions engaged with and walked in nature in combined groups each numbering four to seven people. Had this not been part of the process, however, the effects of unpredictable weather or other external influences might have adversely affected the nature experience and impacted on the ability for certain conditions to be inspired by or to connect with nature. Using the traditional design of one condition within a session would have prevented us from studying the participants in a more authentic environment for group nature walks, and may fail to replicate normal situations for nature walk groups in which members engage with nature differently. To manage the issues of independence, participants were instructed to concentrate on their assigned task and not to communicate with others during the experiment. It is likely therefore that such instruction would attenuate the effects of the study, but would also lessen the risk of dependencies.

It is also unclear whether the tasks in the two conditions were equivalent in terms of cognitive demands. No quantitative measure was taken of how carefully those allocated to the focussed attention condition paid attention to nature. In this current study, the intention in having one group count their footsteps and recount an experience was to inhibit their senses and their ability to attend to the environment. To achieve this, qualitative data was collected using the activity sheet, which provided some evidence that the participants were engaged in their specific tasks during the walk.

Next, even with randomised assignment there is a possible assignment bias, as the state measure of connectedness with nature was collected at post-test but not at pre-test. Our estimate of individual differences between conditions was based solely on the trait measure of connectedness with nature collected at pre-test. For a more robust comparison, future research might consider measuring both states of connectedness with nature at both pre- and post-test.

Despite its small effects, our study has raised some future research directions for investigation. The first of these relates to the importance of further research to investigate the optimal dosage of nature exposure. It is plausible that longer periods of exposure may result in increased improvements in divergent thinking. We suggest two ways of investigating the dose 
RUNNING TITLE: Effects of the nature-creativity relationship

600 response of nature exposure. First, future research needs to investigate the dose effects of such exposure. In principle, a between subject design with duration as the independent variable may shed light on this issue of exploring the effect of an optimal dosage of nature exposure on creativity and other cognitive measures. Second, researchers may wish to study the impact of repeated exposure to nature over time, so as to examine whether repeated nature experiences are more efficient in achieving optimal cognitive effects. Another future research direction would be to extend this study and compare the pre- and post-test effects of focussed versus unfocussed engagement conditions in both natural and urban environments. Although the comparison of nature and urban conditions may seem somewhat biased given their opposite environmental characteristics, such a study might test whether effects of contact with nature are due to the natural environment or attention levels. There is a possibility that it would reveal information regarding the process of focussed and unfocussed attention in different environments.

\section{Implications}

This study has stimulated us to consider how we can enrich people's engagement with nature. In the long term, it would be prudent to cultivate people's sense of connectedness with nature and promote the socio-emotional and cognitive benefits resulting from nature experiences. While some researchers suggest that spending more time in the natural world and having direct contact with it would increase connectedness with nature (Geng, Xu, Ye, Zhou, \& Zhou, 2015), others argue that the way we engage with nature influences the strength of our connection to it (Vining et al., 2008). The consequences of nature experiences appear to depend on how people engage with what is around them and on the depth of their psychological connection with nature. Focussed engagement with nature may play an important role in developing a stronger sense of connectedness with it, and this may in turn influence related variables such as creativity.

Judging from an educational perspective, practitioners may need to think of ways to stimulate people to feel more connected with nature. One method of focussing engagement with nature links to a current outdoor education approach, 'slow pedagogy of place' (Payne \& Wattchow, 2010). Such an approach involves slowing down and interacting with the natural world, perhaps observing the natural surroundings more closely, or interacting with the environment (e.g., planting a seedling and nurturing it over time as it grows into a plant or tree). Those who receive exposure to new nature experiences may form thereby an emotional and cognitive bond with nature, and may in turn increase any potential benefits to be reaped from such natural experiences and connectedness.

\section{CONCLUSION}

In sum, the findings of this study suggest that connectedness with nature is a potential variable for understanding how engagement with nature can increase creative performance. This indicates that an appreciation of the ways nature affects humans may be important for improving human well-being and performance. Previous research has highlighted that people who have a stronger sense of connectedness with nature are more likely to exhibit creative behaviour (Leong et al., 2014). Given the importance of developing a creative society for economic progress (APEC Human Resources Development Working Group, 2011; Trilling \& Fadel, 2009), the creative benefits of exposure to the natural environment will hopefully provide further 
RUNNING TITLE: Effects of the nature-creativity relationship

644 motivation for people to support an active outdoor lifestyle and relevant policy in promotion of 645 this.

\section{CONFLICT OF INTEREST}

The authors declare that the research was conducted in the absence of any commercial or financial relationships that could be construed as a potential conflict of interest.

\section{AUTHOR CONTRIBUTIONS}

Lai Yin Carmen Leong, Stephen Hill, and Ronald Fischer contributed conception and design of the studies. Leong organised the database, performed the statistical analysis, and wrote the first draft of the manuscript. All authors contributed to manuscript revision, read, and approved the submitted version.

The corresponding author takes primary responsibility for communication with the journal and editorial office during the submission process, throughout the peer review, and during publication. The corresponding author is also responsible for ensuring that the submission adheres to all journal requirements including, but not exclusive to, details of authorship, study ethics and ethics approval, clinical trial registration documents and conflict of interest declaration. The corresponding author should also be available post-publication to respond to any queries or critiques.

\section{ACKNOWLEDGMENT}

The studies were supported by Massey University, Ministry of Education (Singapore), and Karori Sanctuary Trust (who kindly waived the participants' entrance fees to Zealandia). We gratefully acknowledge Professor John McClure's and Associate Professor John Spicer's constructive feedback, the assistance of Dr Xiaodan Gao, whose feedback was so helpful to us, and the valuable contribution of the students who participated in the surveys and experiments.

\section{REFERENCES}

Alawad, A. (2012). Can we bring the natural environment into the art classroom? Can natural sound foster creativity? Educational Research and Review, 7(28), 627-631.

Amabile, T. M. (1983a). The social psychology of creativity. New York: Springer-Verlag.

Amabile, T. M. (1983b). The social psychology of creativity: A componential conceptualization. Journal of Personality and Social Psychology, 45(2), 357-376. doi:http://dx.doi.org/10.1037/0022-3514.45.2.357

Amabile, T. M. (1996). Creativity in context: Update to "the social psychology of creativity". United States: Westview Press.

APEC Human Resources Development Working Group. (2011). Quality in higher education: Identifying, developing and sustaining best practices in the APEC region. Retrieved from http://publications.apec.org/publication-detail.php?pub_id=1204.

Atchley, R. A., Strayer, D. L., \& Atchley, P. (2012). Creativity in the wild: Improving creative reasoning through immersion in natural settings. PLoS ONE, 7(12), 1-3. doi:10.1371/journal.pone.0051474 
RUNNING TITLE: Effects of the nature-creativity relationship

Beghetto, R. A. (2006). Creative self-efficacy: Correlates in middle and secondary students. Creativity Research Journal, 18(4), 447-457. doi:10.1207/s15326934crj1804_4

Bowler, D. E., Buyung-Ali, L. M., Knight, T. M., \& Pullin, A. S. (2010). A systematic review of evidence for the added benefits to health of exposure to natural environments. $B M C$ public health, 10(1), 456-456. doi:10.1186/1471-2458-10-456

Bratman, G. N., Hamilton, J. P., Hahn, K. S., Daily, G. C., \& Gross, J. J. (2015). Nature experience reduces rumination and subgenual prefrontal cortex activation. Proceedings of the National Academy of Sciences, 112(28), 8567-8572. doi:10.1073/pnas.1510459112

Capaldi, C. A., Dopko, R. L., \& Zelenski, J. M. (2014). The relationship between nature connectedness and happiness: A meta-analysis. Frontiers in Psychology, 5. doi:10.3389/fpsyg.2014.00976

Cason, D., \& Gillis, H. L. L. (1994). A meta-analysis of outdoor adventure programming with adolescents. Journal of Experiential Education, 17(1), 40-47. doi:10.1177/105382599401700109

Cohen, J. (1992). A power primer. Psychological Bulletin, 112(1), 155-159. doi:10.1037/00332909.112.1.155

Colella, D., Morano, M., Bortoli, L., \& Robazza, C. (2008). A physical self-efficacy scale for children. Social Behavior and Personality: an international journal, 36(6), 841-841. doi:10.2224/sbp.2008.36.6.841

Dadvand, P., Nieuwenhuijsen, M. J., Esnaola, M., Forns, J., Basagaña, X., Alvarez-Pedrerol, M., ... Sunyer, J. (2015). Green spaces and cognitive development in primary schoolchildren. Proceedings of the National Academy of Sciences. doi:10.1073/pnas.1503402112

Ee, J., Seng, T. O., \& Kwang, N. A. (2007). Styles of creativity: Adaptors and innovators in a Singapore context. Asia Pacific Education Review, 8(3), 364-373. doi:10.1007/bf03026466

Faul, F., Erdfelder, E., Lang, A.-G., \& Buchner, A. (2007). G* Power 3: A flexible statistical power analysis program for the social, behavioral, and biomedical sciences. Behavior research methods, 39(2), 175-191. doi:10.3758/BF03193146

Ferraro, F. M., III. (2015). Enhancement of convergent creativity following a multiday wilderness experience. Ecopsychology, 7(1), 7-11. doi:10.1089/eco.2014.0043

Geng, L., Xu, J., Ye, L., Zhou, W., \& Zhou, K. (2015). Connections with Nature and Environmental Behaviors. PLoS ONE, 10(5), e0127247. doi:10.1371/journal.pone.0127247

Grant, A. M., \& Berry, J. W. (2011). The necessity of others is the mother of invention: Intrinsic and prosocial motivations, perspective taking, and creativity. Academy of Management Journal, 54(1), 73-96. doi:10.5465/AMJ.2011.59215085

Grinde, B., \& Patil, G. G. (2009). Biophilia: Does visual contact with nature impact on health and well-being? International Journal of Environmental Research and Public Health, 6(9), 2332-2343.

Guilford, J. P. (1950). Creativity. American Psychologist, 5(9), 444-454. doi:10.1037/h0063487

Guilford, J. P. (1956). The structure of intellect. Psychological Bulletin, 53(4), 267-293. doi:http://dx.doi.org/10.1037/h0040755

Hans, T. A. (2000). A meta-analysis of the effects of adventure programming on locus of control. Journal of Contemporary Psychotherapy, 30(1), 33-60. doi:10.1023/a:1003649031834 
RUNNING TITLE: Effects of the nature-creativity relationship

Hattie, J., Marsh, H. W., Neill, J. T., \& Richards, G. E. (1997). Adventure education and Outward Bound: Out-of-class experiences that make a lasting difference. Review of Educational Research, 67(1), 43-87. doi:10.3102/00346543067001043

Hayes, A. F. (2012). PROCESS: A versatile computational tool for observed variable mediation, moderation, and conditional process modeling [White paper]. Retrieved from http://www.afhayes.com/public/process2012.pdf

Herzog, T. R., Black, A. M., Fountaine, K. A., \& Knotts, D. J. (1997). Reflection and attentional recovery as distinctive benefits of restorative environments. Journal of Environmental Psychology, 17(2), 165-170. doi:10.1006/jevp.1997.0051

Hoever, I. J., Van Knippenberg, D., van Ginkel, W. P., \& Barkema, H. G. (2012). Fostering team creativity: Perspective taking as key to unlocking diversity's potential. Journal of Applied Psychology, 97(5), 982. doi:http://dx.doi.org.ezproxy.massey.ac.nz/10.1037/a0029159

Kim, K. H. (2005). Can only intelligent people be creative? A meta-analysis. Journal of Advanced Academics, 16(2/3), 57.

Kirton, M. J. (1976). Adaptors and innovators: A description and measure. Journal of Applied Psychology, 61(5), 622-629. doi:10.1037/0021-9010.61.5.622

Lee, C. S., Therriault, D. J., \& Linderholm, T. (2012). On the cognitive benefits of cultural experience: Exploring the relationship between studying abroad and creative thinking. Applied Cognitive Psychology, 768-778. doi:10.1002/acp.2857

Leong, L. Y. C. (2017). Exploring the effects of outdoor activities and connectedness with nature on cognitive styles and creativity. (Doctoral dissertation), Massey University, New Zealand.

Leong, L. Y. C., Fischer, R., \& McClure, J. (2014). Are nature lovers more innovative? The relationship between connectedness with nature and cognitive styles. Journal of Environmental Psychology, 40, 57-63. doi:10.1016/j.jenvp.2014.03.007

Leopold, A. (1949). A sand county almanac. New York: Oxford University Press, Inc.

Leung, A. K.-y., \& Chiu, C.-y. (2010). Multicultural experience, idea receptiveness, and creativity. Journal of Cross-Cultural Psychology, 41(5-6), 723-741. doi:10.1177/0022022110361707

Leung, A. K.-y., Maddux, W. W., Galinsky, A. D., \& Chiu, C.-y. (2008). Multicultural experience enhances creativity: The when and how. American Psychologist, 63(3), 169. doi:http://dx.doi.org/10.1037/0003-066X.63.3.169

Lichtenfeld, S., Elliot, A. J., Maier, M. A., \& Pekrun, R. (2012). Fertile green: Green facilitates creative performance. Personality and Social Psychology Bulletin, 38(6), 784-797. doi:10.1177/0146167212436611

Ma, H.-H. (2009). The effect size of variables associated with creativity: A meta-analysis. Creativity Research Journal, 21(1), 30-42. doi:10.1080/10400410802633400

Markowitz, E. M., Goldberg, L. R., Ashton, M. C., \& Lee, K. (2012). Profiling the "proenvironmental individual": A personality perspective. Journal of Personality, 80(1), 81111. doi:10.1111/j.1467-6494.2011.00721.x

Mayer, F. S., \& Frantz, C. M. (2004). The connectedness to nature scale: A measure of individuals' feeling in community with nature. Journal of Environmental Psychology, 24(4), 503-515. doi:10.1016/j.jenvp.2004.10.001

Mayer, F. S., Frantz, C. M., Bruehlman-Senecal, E., \& Dolliver, K. (2009). Why is nature beneficial? The role of connectedness to nature. Environment and Behavior, 41(5), 607643. doi:10.1177/0013916508319745 
RUNNING TITLE: Effects of the nature-creativity relationship

Mednick, S. A. (1962). The associative basis of the creative process. Psychological review, 69(3), 220-232. doi:10.1037/h0048850

Mortlock, C. (1984). The adventure alternative. Cumbria: Cicerone Press.

Oppezzo, M., \& Schwartz, D. L. (2014). Give your ideas some legs: The positive effect of walking on creative thinking. Journal Of Experimental Psychology: Learning, Memory, And Cognition, 40(4), 1142-1152. doi:http://dx.doi.org/10.1037/a0036577

Payne, P. G., \& Wattchow, B. (2010). Phenomenological deconstruction, slow pedagogy, and the corporeal turn in wild environmental/outdoor education. Canadian Journal of Environmental Education, 14, 16-32.

Runco, M. A. (1986). The discriminant validity of gifted children's divergent thinking test scores. Gifted Child Quarterly, 30(2), 78-82. doi:10.1177/001698628603000207

Ryckman, R. M., Robbins, M. A., Thornton, B., \& Cantrell, P. (1982). Development and validation of a physical self-efficacy scale. Journal of Personality and Social Psychology, 42(5), 891-900. doi:10.1037/0022-3514.42.5.891

Shibata, S., \& Suzuki, N. (2002). Effects of the foliage plant on task performance and mood. Journal of Environmental Psychology, 22(3), 265-265. doi:10.1006/jevp.2002.0232

Shibata, S., \& Suzuki, N. (2004). Effects of an indoor plant on creative task performance and mood. Scandinavian Journal of Psychology, 45(5), 373-381. doi:10.1111/j.14679450.2004.00419.x

Silvia, P. J., Winterstein, B. P., Willse, J. T., Barona, C. M., Cram, J. T., Hess, K. I., . . Richard, C. A. (2008). Assessing creativity with divergent thinking tasks: Exploring the reliability and validity of new subjective scoring methods. Psychology of Aesthetics, Creativity, and the Arts, 2(2), 68. doi:http://dx.doi.org/10.1037/1931-3896.2.2.68

Tam, K.-P. (2013). Dispositional empathy with nature. Journal of Environmental Psychology, 35, 92-104. doi:http://doi.org/10.1016/j.jenvp.2013.05.004

Tierney, P., \& Farmer, S. M. (2002). Creative self-efficacy: Its potential antecedents and relationship to creative performance. The Academy of Management Journal, 45(6), 1137 1148. doi:10.2307/3069429

Trilling, B., \& Fadel, C. (2009). 21st Century Skills: Learning for Life in Our Times. San Francisco, California: John Wiley \& Sons.

Vining, J., Merrick, M. S., \& Price, E. A. (2008). The distinction between humans and nature: Human perceptions of connectedness to nature and elements of the natural and unnatural. Human Ecology Review, 15(1), 1.

Weinstein, N., Przybylski, A. K., \& Ryan, R. M. (2009). Can nature make us more caring? Effects of immersion in nature on intrinsic aspirations and generosity. Personality and Social Psychology Bulletin, 35(10), 1315-1329. doi:10.1177/0146167209341649

Wilson, E. O. (1984). Biophilia: The human bond with other species. Cambridge: Harvard University Press. 
RUNNING TITLE: Effects of the nature-creativity relationship

\section{TABLES}

819

820 Table 1

821 Correlations of Outdoor Creativity Task Scores and Other Psychological Variables.

\begin{tabular}{llrllll}
\hline Variable & $M$ & \multicolumn{1}{c}{$S D$} & Originality & CNS & KAI & CSE \\
\hline Originality & 11.19 & 4.67 & - & & & \\
CNS & 3.37 & .44 & $.28^{* *}$ & - & & \\
KAI & 113.29 & 16.69 & $.18^{*}$ & $.56^{* *}$ & - & \\
CSE & 3.39 & .89 & $.26^{* *}$ & $.35^{* *}$ & $.48^{* *}$ & - \\
PAS & 15.84 & 2.83 & $.18^{*}$ & $.18^{*}$ & $.21^{* *}$ & $.24^{* *}$ \\
\hline
\end{tabular}

822 Note. CNS: Connectedness to Nature Scale; KAI: Kirton's Adaption-Innovation Inventory; CSE:

823 Creative Self-Efficacy Scale; PAS: Perceived Physical Ability Scale for Children.

$824 * p<.05, * * p<.01$

825 
RUNNING TITLE: Effects of the nature-creativity relationship

826 Table 2

827 Hierarchical Multiple Regression Analyses Predicting Creative Scores

\begin{tabular}{|c|c|c|c|}
\hline \multirow{4}{*}{ Variables } & \multicolumn{3}{|c|}{ Originality } \\
\hline & Model 1 & Model 2 & Model 3 \\
\hline & $B$ & $B$ & $B$ \\
\hline & $95 \% \mathrm{CI}$ & $95 \%$ CI & $95 \%$ CI \\
\hline & .01 & .16 & .03 \\
\hline Age & {$[-1.04,1.06]$} & {$[-.87,1.18]$} & {$[-.97,1.04]$} \\
\hline & -1.85 & -2.14 & -2.25 \\
\hline Gender & {$[-3.40,-.29]$} & {$[-3.68,-.60]$} & {$[-3.75,-.75]$} \\
\hline & -1.76 & -1.49 & -1.44 \\
\hline $\begin{array}{l}\text { Educational } \\
\text { Status }\end{array}$ & {$[-3.50,-.02]$} & {$[-3.20, .23]$} & {$[-3.11, .24]$} \\
\hline Outdoor & .11 & .07 & .10 \\
\hline Experience & {$[-.16, .39]$} & {$[-.20, .34]$} & {$[-.17, .36]$} \\
\hline & .33 & .24 & .22 \\
\hline PAS & {$[.06, .60]$} & {$[-.03, .52]$} & {$[-.05, .49]$} \\
\hline KAI & & $\begin{array}{c}.01 \\
{[-.04, .06]}\end{array}$ & $\begin{array}{l}-.03 \\
{[-.09, .02]}\end{array}$ \\
\hline CSE & & $\begin{array}{l}1.23 \\
{[.25,2.22]}\end{array}$ & $\begin{array}{l}1.10 \\
{[.14,2.06]}\end{array}$ \\
\hline CNS & & & $\begin{array}{l}2.87 \\
{[.83,4.91]}\end{array}$ \\
\hline$R^{2}$ & .10 & .15 & .20 \\
\hline$\Delta R^{2}$ & .10 & .06 & .06 \\
\hline Adjusted $R^{2}$ & .06 & .11 & .15 \\
\hline$F$ for $\Delta R^{2}$ & $2.83^{*}$ & $4.30^{*}$ & $7.77 * *$ \\
\hline
\end{tabular}

828 Note. Gender: 1=Girl and 2=Boy; PAS: Perceived Physical Ability Scale for Children; KAI:

829 Kirton's Adaption-Innovation Inventory; CSE: Creative Self-Efficacy Scale; CNS:

830 Connectedness to Nature Scale.

$831 * p<.05, * * p<.01$ 
RUNNING TITLE: Effects of the nature-creativity relationship

833 Table 3

834

835 Descriptive Statistics and Correlations between Connectedness with Nature and Originality 836 Scores.

\begin{tabular}{lcccl}
\hline Variable & $M$ & $S D$ & CNS & Originality time 1 \\
\hline CNS & 3.69 & .68 & - & \\
Originality time one & 14.65 & 4.64 & .12 & - \\
Originality time two & 14.71 & 4.52 & $.25^{*}$ & $.80^{* *}$ \\
\hline
\end{tabular}

837 Note. CNS: Connectedness to Nature Scale at time 2.

$838 * p<.05, * * p<.01$ 
RUNNING TITLE: Effects of the nature-creativity relationship

839 FIGURE LEGENDS

840

841

To insert Figure 1 and Figure 2. 